\title{
Expression of cytokeratin 19 in the cytosolic fraction of thyroid lesions: ELISA and Western blot analysis
}

\author{
ANNA KRZESLAK ${ }^{1}$, ZUZANNA GAJ $^{1}$, LECH POMORSKI $^{2}$ and ANNA LIPINSKA ${ }^{1}$ \\ ${ }^{1}$ Department of Cytobiochemistry, University of Lódz, Banacha 12/16, 90-237 Lódz; ${ }^{2}$ Department of \\ Endocrinological and General Surgery, Medical University of Lódz, Pabianicka 62, 95-513 Lódz, Poland
}

Received January 31, 2008; Accepted March 31, 2008

\begin{abstract}
Cytokeratin 19 (CK19) is one of the most frequently studied immunohistochemical markers in thyroid pathology. The results of several studies suggest that CK19 may be useful in the diagnosis of papillary carcinoma, where it has been shown to have strong diffuse cytoplasmic reactivity. However, the published results vary, and the utility of CK19 in the diagnosis of thyroid lesions is controversial. The aim of this study was to evaluate, by Western blot analysis and the enzyme-linked immunosorbent assay (ELISA), the expression of CK19 in the cytosolic fraction obtained from 125 specimens of various thyroid lesions: nodular goiters, follicular adenomas, papillary carcinomas, follicular carcinomas and anaplastic carcinomas. The analysis of CK19 expression using the ELISA showed that the majority of papillary carcinoma cases had a much higher level of CK19 than did nodular goiters and adenomas $(\mathrm{P}<0.001)$. Western blot analysis revealed the presence of CK19 in $66 \%$ of papillary carcinoma cases. CK19 expression was also found in 11,22, 25 and $25 \%$ of nodular goiters, follicular adenomas, and follicular and anaplastic carcinomas, respectively. The results demonstrate that the evaluation of CK19 expression may be helpful in distinguishing papillary carcinoma from other benign and malignant thyroid nodules, but cannot by itself be used to establish a diagnosis.
\end{abstract}

\section{Introduction}

Cytokeratins (CKs) are among the major structural proteins of the epithelial cells, occurring as a cytoplasmic network of 10to 12-nm-wide intermediate filaments. The primary function of CKs is to protect the epithelial cells from mechanical and non-mechanical stresses (1). However, recent data suggest they serve other functions as well, for example in cell signaling, stress response and apoptosis (2-6). The expression profile of CKs depends on epithelial type and may be altered during

Correspondence to: Professor Anna Lipinska, Department of Cytobiochemistry, University of Lódz, Banacha 12/16, 90-237 Lódz, Poland

E-mail: annal@biol.uni.lodz.pl

Key words: cytokeratin 19, thyroid lesions, Western blot analysis carcinogenesis. Neoplastic epithelia may preserve the original CKs of their normal progenitor cells, or may develop various new types (7). CKs play an important role in the regulation of tumor cell migration and invasion. Chu et al (8) demonstrated that mouse L cells transfected with the human CKs 8 and 18 had higher migratory and invasive abilities than parental and control-transfected cells. Direct evidence has been provided which indicates that the overexpression of CK19 in hepatocellular carcinoma cells is related to their metastatic behavior (9).

Cytokeratin 19 (CK19), a low molecular weight keratin $(40 \mathrm{kDa})$, is one of the most frequently studied markers in thyroid pathology. CK19 is expressed differentially in various types of thyroid lesions. Although CK19 expression is not specific to malignancy, malignant transformation is usually accompanied by an increased level of CK19 expression. The results of several immunohistochemical and immunocytochemical studies have shown that CK19 may be useful, especially in the diagnosis of papillary carcinoma (10-15). Some authors claim that the strong and diffuse reactivity of CK19 in papillary carcinoma can be helpful in differential diagnosis, distinguishing it from other benign and malignant lesions. Nonetheless, the utility of CK19 in the diagnosis of papillary thyroid carcinomas is still in question. In some studies, the positive reaction of CK19 was also found in a large number of follicular carcinomas, follicular adenomas, nodular goiters and even normal tissues (7,16-18). However, it should be stressed that CK19 is typically only focally present in goiters and adenomas, while its expression in papillary carcinomas is strong and uniform. On the other hand, the finding that $50 \%$ or more of follicular carcinoma specimens are also CK19 positive suggests that CK19 reactivity is not absolutely reliable in differentiating papillary and follicular carcinoma $(7,12,17$, $19,20)$.

The aim of this study was to evaluate the expression of CK19 in the cytosolic fraction of benign and malignant thyroid lesions using immunological methods, namely Western blot analysis and the enzyme-linked immunosorbent assay (ELISA), rather than immunohistochemical techniques.

\section{Materials and methods}

Surgical specimens. Surgical specimens were obtained from 125 patients (29 males and 96 females) who underwent surgery for nodular thyroid disease. The mean age of the patients was 52 years (range 11-83 years). The study was per- 
formed on specimens from 30 non-neoplastic lesions (nodular goiters), 30 cases of follicular adenomas, 8 cases of follicular carcinomas, 53 cases of papillary carcinomas and 4 cases of anaplastic carcinomas. All cases of follicular carcinoma showed the presence of capsular and vascular invasions, but no cases were widely invasive. Cases of papillary carcinoma were classified as stage I or II $\left(\mathrm{T}_{1-2} \mathrm{~N}_{0-1} \mathrm{M}_{0}\right)$ according to the TNM staging system accepted by the International Union Against Cancer (UICC, 2002).

Isolation of cytosolic fraction. The supernatant obtained after the separation of the nuclei from the homogenate of thyroid pathological specimens was used for cytosolic fraction isolation (21). This supernatant was subjected to centrifugation in order to remove the residues of nuclei and the mitochondrial and microsomal fractions. The supernatant obtained after centrifugation at $100,000 \times \mathrm{g}$ for $1 \mathrm{~h}$ was considered the cytosolic fraction.

Enzyme-linked immunosorbent assay. For semi-quantitative analysis of CK19 expression in the cytosol, the ELISA was used. Samples of cytosolic fraction to be assayed for the presence of CK19 were diluted to a final concentration of $2.5 \mu \mathrm{g} / \mathrm{ml}$ in $0.1 \mathrm{M}$ carbonate buffer, $\mathrm{pH}$ 9.8. The diluted samples $(100 \mu 1)$ were added to the wells of 96-well microtiter polystyrene plates (Bio-Rad, Hercules, CA, USA). The attachment of proteins to the wells was effected by overnight incubation at $4^{\circ} \mathrm{C}$, following which the plates were washed three times with Tris-buffered saline containing $0.05 \%$ Tween-20 (TTBS). The non-specific binding sites were blocked by the addition to each well of $200 \mu 12 \%$ BSA in TTBS buffer, followed by incubation for $1 \mathrm{~h}$ at room temperature. Microtiter plates were again washed three times with TTBS and incubated for $1 \mathrm{~h}$ at room temperature with $100 \mu 1$ per well of mouse monoclonal anti-CK19 antibody (Santa Cruz Biotechnology, Santa Cruz, CA, USA) diluted 1:1000 in TTBS. After the plates were washed three times with TTBS buffer, goat anti-mouse antibodies conjugated with horseradish peroxidase (100 $\mu 1$ per well) (Santa Cruz Biotechnology) were added (1:5000 dilution of antibodies). The plates were incubated for $1 \mathrm{~h}$ at room temperature and washed with three changes of TTBS. The color reaction was developed by adding $100 \mu 1$ per well of peroxidase substrate [0.04\% 1,2-phenylenediamine dihydrochloride/OPD (Sigma-Aldrich Co., St. Louis, $\mathrm{MO}, \mathrm{USA}$ ) in $0.1 \mathrm{M}$ citric acid phosphate buffer ( $\mathrm{pH}$ 5.0) and $\mathrm{H}_{2} \mathrm{O}_{2}$ ]. The reaction was terminated by the addition of $150 \mu \mathrm{l}$ $\mathrm{H}_{2} \mathrm{SO}_{4}$ to each well. The absorbance of the wells was measured at $490 \mathrm{~nm}$ with an automatic microplate reader (Bio-Rad, model 550).

Western blot analysis. The samples (50 $\mu \mathrm{g}$ protein/lane) of homogenate and cytosolic proteins of the different types of thyroid lesions were resolved by $8 \%$ SDS-PAGE (22) and electroblotted onto Immobilon-P transfer membranes (Millipore, Bedford, MA, USA) (23). The blots were treated for $2 \mathrm{~h}$ with blocking reagent $(0.5 \%$ casein in TBS) then incubated for $1 \mathrm{~h}$ with mouse monoclonal anti-CK19 antibody in a 1:1000 dilution. After being washed three times with TBS, the membranes were incubated for $1 \mathrm{~h}$ with goat anti-mouse antibodies conjugated with horseradish peroxidase, added in
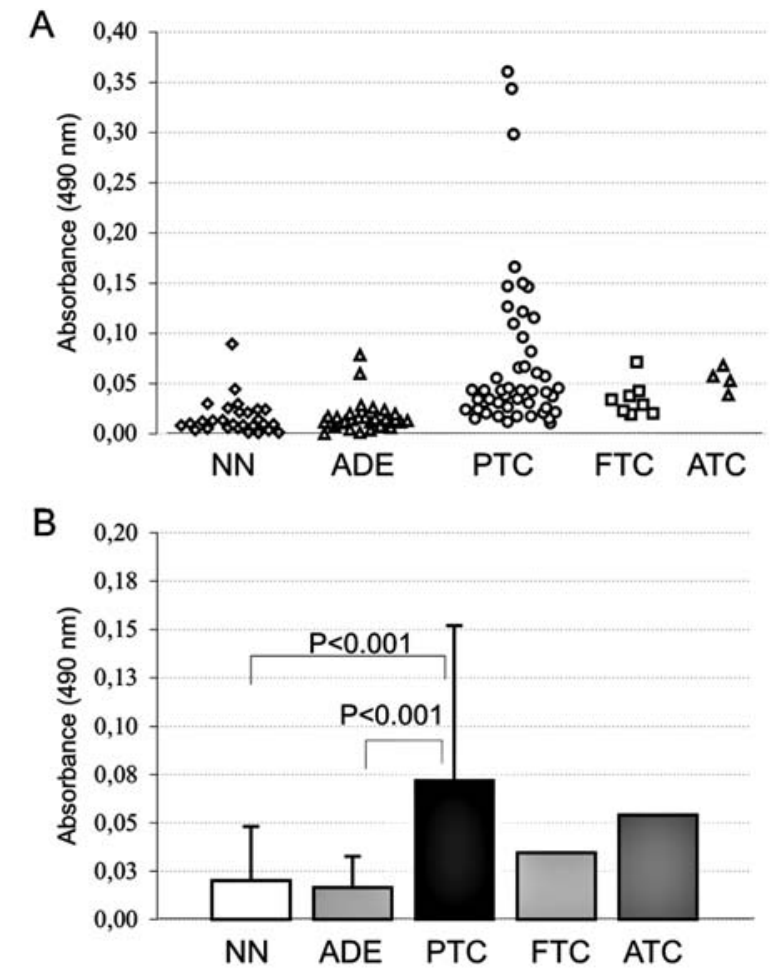

\begin{tabular}{|c|c|c|}
\hline Lesion & No. & $\overline{\mathbf{A}} \pm \mathbf{s}$ \\
\hline NN & 30 & $0.020 \pm 0.028$ \\
\hline ADE & 30 & $0.017 \pm 0.016$ \\
\hline PTC & 48 & $0.072 \pm 0.080$ \\
\hline FTC & 8 & 0.035 \\
\hline ATC & 4 & 0.054 \\
\hline
\end{tabular}

Figure 1. (A) Analysis of CK19 expression in the cytosolic fraction of thyroid pathological specimens with the ELISA, and (B) the mean values for each group. NN, non-neoplastic; ADE, adenoma; PTC, papillary carcinoma; FTC, follicular carcinoma; ATC, anaplastic carcinoma specimens.

a 1:5000 dilution. The membranes were again washed three times with TBS and the color reaction was carried out by incubating the membranes with chromogenic substrate for peroxidase, 4-chloro-1-naphtol and $\mathrm{H}_{2} \mathrm{O}_{2}$.

Measurement of protein concentration. Protein content was assayed using bovine serum albumin as a standard by the method of Lowry et al (24).

Statistical analysis. Statistical analysis was performed using the computer program Statistica version 5.5 (StatSoft Inc.). The groups were compared using the Mann-Whitney rank sum test. A P-value $<0.05$ was considered statistically significant.

\section{Results}

For semi-quantitative analysis of CK19 expression in the cytosolic fraction of thyroid lesions, the ELISA was used. Fig. 1A illustrates the level of CK19 expression in individual cases of the following thyroid lesions: non-neoplastic lesions (nodular goiters), follicular adenomas, papillary carcinomas, follicular carcinomas and anaplastic carcinomas. Fig. 1B shows the mean values for each group. The results obtained 
Table I. Expression of cytokeratin 19 in various thyroid lesions analyzed by Western blotting.

\begin{tabular}{|c|c|c|c|c|c|c|}
\hline \multirow[t]{2}{*}{ Histologic diagnosis } & \multirow[t]{2}{*}{ No. of cases } & \multirow[t]{2}{*}{ CK19 negative } & \multicolumn{3}{|c|}{ CK19 positive ${ }^{a}$} & \multirow[t]{2}{*}{$\%$ positive } \\
\hline & & & 1 & 2 & 3 & \\
\hline Nodular goiters & 28 & 25 & 1 & 1 & 1 & 11 \\
\hline Follicular adenomas & 27 & 21 & 4 & 1 & 1 & 22 \\
\hline Papillary carcinomas & 53 & 18 & 13 & 7 & 15 & 66 \\
\hline Follicular carcinomas & 4 & 3 & & 1 & & 25 \\
\hline Anaplastic carcinomas & 4 & 3 & & 1 & & 25 \\
\hline
\end{tabular}

${ }^{\mathrm{a}}$, weakly; 2 , moderately; 3 , strongly positive.

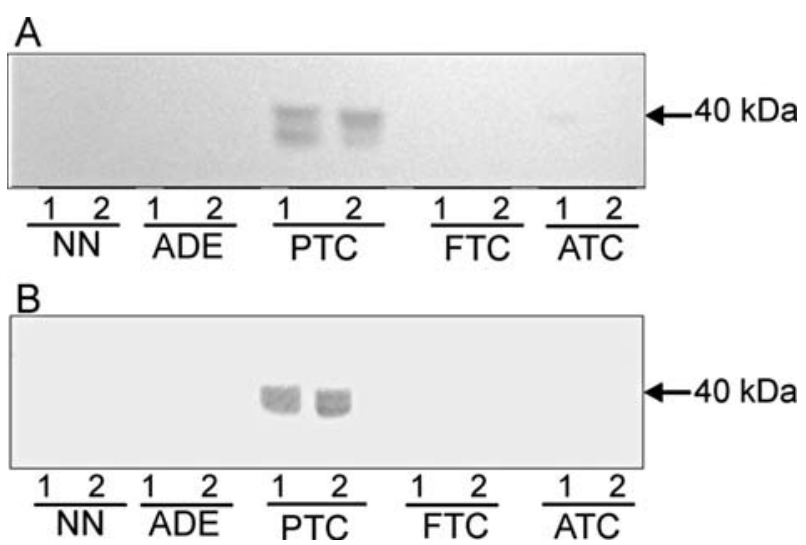

Figure 2. CK19 expression in thyroid pathological specimens. Homogenate (A) and cytosolic (B) proteins $(50 \mu \mathrm{g})$ from non-neoplastic lesions $(\mathrm{NN})$, follicular adenomas (ADE), papillary carcinomas (PTC), follicular carcinomas (FTC) and anaplastic carcinomas (ATC) electrophoresed on $8 \%$ acrylamide slab gels were transferred onto Immobilon-P membranes and tested with anti-CK19 antibody.

with the ELISA revealed a significant difference between the CK19 expression of papillary carcinomas and benign lesions, i.e. nodular goiters and follicular adenomas. The majority of samples of papillary carcinoma indicated stronger reactivity with the CK19 antibody than did non-neoplastic lesions and adenomas $(\mathrm{P}<0.001)$. There were no statistically significant differences between adenomas and non-neoplastic lesions $(P>0.05)$. The low number of follicular carcinomas and anaplastic carcinomas precluded statistical analysis, but it appears that in both types of cancer CK19 expression is lower than in papillary carcinoma and higher than in non-neoplastic lesions and adenomas.

For Western blot analysis, $50 \mu \mathrm{g}$ of homogenate and cytosolic proteins were separated by $8 \%$ SDS-PAGE and electrophoretically transferred onto an Immobilon-P membrane. Equal protein loading was confirmed by Ponceau $\mathrm{S}$ staining of the transferred proteins (data not shown). Immunoblotting as well as the ELISA were performed using antiCK19 monoclonal antibody and horseradish peroxidaseconjugated secondary antibody, and detection was by color reaction with 4-chloro-1 naphtol as a substrate for peroxidase. The representative results of CK19 expression in the different thyroid lesions obtained after Western blotting are shown in
Fig. 2 and summarized in Table I. Of the 28 analyzed nodular goiter specimens, CK19 was positive in only 3 cases (11\%). Six of the 27 (22\%) follicular adenoma specimens showed reactivity with the CK19 antibody. Only in one case of nodular goiter and one case of follicular adenoma was the intensity of the band corresponding to CK19 extremely high. Of the 53 papillary carcinoma cases, CK19 was positive in $66 \%(35 / 53)$. In $15(28 \%)$ cases expression was extremely high, and in 7 (13\%) it was moderate. One of the $4(25 \%)$ cases of follicular and anaplastic carcinoma was CK19-positive.

The additional band observed below the one corresponding to CK19 may represent the product of its degradation (Fig. 2A). It has been reported that, upon its release from tumor cells, CK fragments can be detected in a number of body fluids, including blood (25).

\section{Discussion}

The prognosis and management of thyroid nodular diseases depend on their diagnosis. Several markers of malignancy have been investigated, but all present some advantages and some limitations. The utility of CK19 in the diagnosis of thyroid carcinomas is controversial. To date, studies concerning the expression of CK19 in thyroid lesions have been limited to immunohistochemistry and immunocytochemistry, and published results vary (Table II). Several authors have reported $70-100 \%$ positive cases of papillary carcinomas. There are wide discrepancies between the results concerning CK19 expression in adenomas and in follicular carcinomas (5-100\% and $21-100 \%$, respectively). The reasons for the discrepancies in the results concerning CK19 expression in thyroid lesions as reported by different authors are unclear, but may partially be due to the subjectivity involved in assessing positive expression. Sahoo et al (18) found CK19 expression in a high percentage of non-neoplastic lesions and benign tumors, but considered the cases positive even when CK19 was expressed in $<5 \%$ of tumor cells. Other researchers considered CK 19 expressed when at least $10 \%$ of cells were positive (26). Barroeta et al (28), who studied the value of several immunohistochemical markers in the diagnosis of follicular-derived lesions of the thyroid, scored staining as positive when $>25 \%$ of the lesional cells showed positive immunostaining. CK19 was positive in $70 \%$ of malignant thyroid lesions and in $34 \%$ of benign ones. 
Table II. Expression of cytokeratin 19 in thyroid lesions analyzed by immunohistochemistry (summary of main published results).

\begin{tabular}{|c|c|c|c|c|c|}
\hline \multicolumn{5}{|c|}{ Thyroid lesions } & \multirow[b]{2}{*}{$\begin{array}{l}\text { Author/ } \\
\text { Refs. }\end{array}$} \\
\hline Nodular goiters & $\begin{array}{l}\text { Follicular } \\
\text { adenomas }\end{array}$ & $\begin{array}{c}\text { Papillary } \\
\text { carcinomas }\end{array}$ & $\begin{array}{l}\text { Follicular } \\
\text { carcinomas }\end{array}$ & $\begin{array}{l}\text { Anaplastic } \\
\text { carcinomas }\end{array}$ & \\
\hline- & - & $100 \%(41 / 41)$ & $100 \%(10 / 10)$ & - & Fonseca et al (20) \\
\hline $100 \%(89 / 89)$ & $91 \%(49 / 54)$ & $100 \%(137 / 137)$ & $86 \%(19 / 22)$ & - & Miettinen et al (17) \\
\hline- & - & $100 \%(86 / 86)$ & $68 \%(13 / 19)$ & $76 \%(19 / 25)$ & Lam et al (7) \\
\hline- & $100 \%(20 / 20)$ & $100 \%(15 / 15)$ & - & - & Sahoo et al (18) \\
\hline- & $78 \%(7 / 9)$ & $100 \%(16 / 16)$ & $57 \%(4 / 7)$ & - & Cerilli et al (12) \\
\hline- & $25 \%(5 / 20)$ & $100 \%(26 / 26)$ & $42 \%(5 / 12)$ & $(1 / 1)$ & Beesley and McLaren (10) \\
\hline- & - & $70 \%(26 / 37)$ & - & - & Prasad et al (26) \\
\hline- & $22 \%(2 / 9)$ & $100 \%(67 / 67)$ & $47 \%(14 / 30)$ & $70 \%(7 / 10)$ & Choi et al (11) \\
\hline- & $33 \%(6 / 18)$ & $73 \%(61 / 84)$ & $21 \%(8 / 38)$ & $(0 / 2)$ & De Matos et al (16) \\
\hline $31 \%(9 / 29)$ & $5 \%(1 / 21)$ & $72 \%(48 / 67)$ & $50 \%(3 / 6)$ & $25 \%(1 / 4)$ & Prasad et al (19) \\
\hline- & - & $81 \%(93 / 115)$ & - & - & Shin et al (27) \\
\hline
\end{tabular}

The inconsistent results concerning the immunoreactivity of CK19 in thyroid lesions may also be explained by variations in fixation and embedding methods. Tissue staining is dependent on the handling and processing of the tissue prior to staining, and the interpretation of the results is also crucial. In some cases, thyroid tumor cells show only borderline positive reactions, whereas in others the reaction is diffuse. In addition, some portions of tissue present clusters of stained cells while other portions do not. At times, the marker is restricted to only a few scattered cells.

It has been suggested that the examination of cytologic specimens is more useful than that of histologic specimens, as immunocytochemical study can be carried out before the operation $(14,15)$. Hirokawa et al $(15)$, during immunocytochemical analysis of thyroid lesion smears, found that staining patterns differed between papillary carcinomas, adomatous goiters and follicular neoplasms. While the staining pattern of papillary carcinoma was mainly pancytoplasmic, in adomatous goiters and follicular neoplasms the immunoreactivity of the cell membrane tended to be stronger than that of the intracytoplasm.

In the present study, the utility of CK19 in the diagnosis of thyroid lesions was evaluated using methods other than immunohistochemisty. Taking into account the fact that CK19 has primarily cytoplasmic distribution in papillary carcinomas, we decided to compare CK19 expression in the cytosolic fraction obtained from different types of thyroid lesions. During cytosolic fraction isolation, all membrane fractions are removed; therefore, CK19 in the cytosolic fractions of goiters and adenomas should be less abundant. The results obtained with the ELISA show much higher CK19 expression in papillary carcinomas than in nodular goiters and adenomas. In 17 of $48(35 \%)$ cases of papillary carcinomas, absorbance was extremely high in comparison with the other lesions. However, the differences between papillary carcinomas and the other carcinomas remain unclear. The low number of cases of follicular and anaplastic carcinomas prevented us from reaching a conclusion concerning the utility of CK19 in distinguishing between papillary and other types of carcinoma.

Western blot analysis revealed the presence of CK19 in the cytosol of $66 \%$ of papillary carcinoma cases, and in only 11 and $22 \%$ of nodular goiter and follicular adenoma cases, respectively. It is important to note that the band corresponding to CK19 was usually more intense in cases of papillary carcinoma than in other thyroid lesions. The much higher percentage of positive reactions in the case of papillary carcinomas confirms the results obtained from immunohistochemistry studies, which suggest the utility of CK19 expression analysis in papillary carcinoma diagnosis. However, in our experimental conditions, $>30 \%$ of cases of papillary carcinoma did not show the presence of CK19.

In conclusion, these results confirm that the evaluation of CK19 may be helpful in the diagnosis of papillary carcinoma. In accordance with the results of previous immunohistochemical studies, our data reveal a marked upregulation of CK19 expression in papillary carcinomas, which is in particular contrast with the low levels of CK19 expression observed in follicular adenomas and nodular goiters. At least one third of papillary carcinomas showed extremely high expression of CK19. However, we must emphasize that CK19 is not a conclusive marker for papillary carcinoma, and cannot by itself be used to establish a diagnosis.

\section{Acknowledgements}

This study was supported by grant 505/362 from the University of Lódz.

\section{References}

1. Coulombe PA and Omary MB: Hard and soft principles defining the structure, function and regulation of keratin intermediate filaments. Curr Opin Cell Biol 14: 110-122, 2002. 
2. Gilbert S, Loranger A and Marceau N: Keratins modulate c-Flip/extracellular signal-regulated kinase 1 and 2 antiapoptotic signaling in simple epithelial cells. Mol Cell Biol 24: 7072-7081, 2004.

3. Reichelt J, Furstenberger G and Magin TM: Loss of keratin 10 leads to mitogen-activated protein kinase (MAPK) activation, increased keratinocyte turnover, and decreased tumor formation in mice. Invest Dermatol 123: 973-981, 2004.

4. Ku NO and Omary MB: A disease- and phosphorylation-related nonmechanical function for keratin 8. J Cell Biol 174: 115-125, 2006.

5. Tao GZ, Toivola DM, Zhou O, Strnad P, Xu B, Michie SA and Omary MB: Protein phosphatase-2A associates with and dephosphorylates keratin 8 after hyposmotic stress in a site- and cell-specific manner. J Cell Sci 119: 1425-1432, 2006

6. Galarneau L, Loranger A, Gilbert S and Marceau N: Keratins modulate hepatic cell adhesion, size and $\mathrm{G}_{1} / \mathrm{S}$ transition. Exp Cell Res 313: 179-194, 2007.

7. Lam KY, Lui MC and Lo CY: Cytokeratin expression profiles in thyroid carcinomas. Eur J Surg Oncol 27: 631-635, 2001.

8. Chu YW, Runyan RB, Oshima RG and Hendrix MJC: Expression of complete keratin filaments in mouse $\mathrm{L}$ cells augments cell migration and invasion. Proc Natl Acad Sci USA 90: 4261-4265, 1993.

9. Ding SJ, Li Y, Tan YX, Jiang MR, Tian B, Liu YK, Shao XX, Ye SL, Wu JR, Zeng R, Wang HY, Tang ZY and Xia QC: From proteomic analysis to clinical significance. Overexpression of cytokeratin 19 correlates with hepatocellular carcinoma metastasis. Mol Cell Proteomics 3: 73-81, 2004.

10. Beesley MF and McLaren KM: Cytokeratin 19 and galectin-3 immunohistochemistry in the differential diagnosis of solitary thyroid nodules. Histopathology 41: 236-243, 2002.

11. Choi YL, Kim MK, Suh JW, Han J, Kim JH, Yang JH and Nam SJ: Immunoexpression of HBME-1, high molecular weight cytokeratin, cytokeratin 19 , thyroid transcription factor-1 and E-cadherin in thyroid carcinomas. J Korean Med Sci 20: 853-859, 2005.

12. Cerilli LA, Mills SE, Rumpel CA, Dudley TH and Moskaluk CA: Interpretation of RET immunostaining in follicular lesions of the thyroid. Am J Clin Pathol 118: 186-193, 2002.

13. Nasser SM, Pitman MB, Pilch BZ and Faquin WC: Fine-needle aspiration biopsy of papillary thyroid carcinoma. Diagnostic utility of cytokeratin 19 immunostaining. Cancer Cytopathol 90: 307-312, 2000.

14. Khurana KK, Truong LD, LiVolsi VA and Baloch ZW: Cytokeratin 19 immunolocalization in cell block preparation of thyroid aspirates. An adjunct to fine-needle aspiration diagnosis of papillary thyroid carcinoma. Arch Pathol Lab Med 127: 579-583, 2003.
15. Hirokawa M, Inagaki A, Kobayashi H, Kanahara T, Manabe T and Sonoo H: Expression of cytokeratin 19 in cytologic specimens of thyroid. Diagn Cytopathol 22: 197-198, 2000.

16. De Matos PS, Ferreira AP, De Oliveira Facuri F, Assumpção LVM, Metze K and Ward LS: Usefulness of HBME-1, cytokeratin 19 and galectin-3 immunostaining in the diagnosis of thyroid malignancy. Histopathology 47: 391-401, 2005.

17. Miettinen M, Kovatich AJ and Kärkkäinen P: Keratin subsets in papillary and follicular thyroid lesions. A paraffin section analysis with diagnostic implications. Virchows Arch 431: 407-413, 1997.

18. Sahoo S, Hoda SA, Rosai J and DeLellis RA: Cytokeratin 19 immunoreactivity in the diagnosis of papillary thyroid carcinoma. Am J Clin Pathol 116: 696-702, 2001.

19. Prasad MJ, Pellegata NS, Huang Y, Nagaraja HN, De la Chapelle A and Kloos RT: Galectin-3, fibronectin-1, CITED-1, HBME-1 and cytokeratin 19 immunohistochemistry is useful for the differential diagnosis of thyroid tumors. Mod Pathol 18: 48-57, 2005.

20. Fonseca E, Nesland JM, Höie J and Sobrinho-Simões M: Pattern of expression of intermediate cytokeratin filaments in the thyroid gland: an immunohistochemical study of simple and stratified epithelial-type cytokeratins. Virchows Arch 430: 239-245, 1997.

21. Krzeslak A, Pomorski L, Gaj Z and Lipinska A: Differences in glycosylation of intracellular proteins between benign and malignant thyroid neoplasms. Cancer Lett 196: 101-107, 2003.

22. Laemmli UK: Cleavage of structural proteins during the assembly of the head of bacteriophage T4. Nature 227: 680-685, 1970

23. Towbin H, Staehelin T and Gordon J: Electrophoretic transfer of proteins from polyacrylamide gels to nitrocellulose sheets; procedure and some applications. Proc Natl Acad Sci USA 76: 4350-4355, 1979.

24. Lowry OH, Rosebrough NJ, Farr AL and Randall RJ: Protein measurements with the Folin phenol reagent. J Biol Chem 193: 262-275, 1951.

25. Barak V, Goike H, Panaretakis KW and Einarsson R: Clinical utility of cytokeratins as tumor markers. Clin Biochem 37: 529-540, 2004.

26. Prasad ML, Huang Y, Pellegata NS, de la Chapelle A and Kloos RT: Hashimoto's thyroiditis with papillary thyroid carcinoma (PTC)-like nuclear alterations express molecular markers of PTC. Histopathology 45: 39-46, 2004.

27. Shin E, Chung WY, Yang WI, Park CS and Hong SW: RET/PTC and CK19 expression in papillary thyroid carcinoma and its clinicopathologic correlation. J Korean Med Sci 20: 98-104, 2005.

28. Barroeta JE, Baloch ZW, Lal P, Pasha TL, Zhang PJ and LiVolsi VA: Diagnostic value of differential expression of CK19, galectin-3, HBME-1, ERK, RET, and p16 in benign and malignant follicular-derived lesions of the thyroid: an immunohistochemical tissue microarray analysis. Endocr Pathol 17: 225-234, 2006. 